\section{RESEARCH ROUND-UP}

Gums and kidneys

In a study of black people with normal kidney function in Philadelphia, those with severe periodontal disease developed chronic kidney disease at four times the rate of those without severe periodontal disease. The study was due to be presented at ASN Kidney Week 2014.

Hair and enamel

Keratins, proteins associated with strong hair, are important for tooth enamel integrity. ${ }^{1}$ Researchers found that individuals with mutations in hair keratin genes are prone to cavities. Tooth enamel from individuals with keratin mutations had abnormal structure resulting in weakness.

1. Duverge 0, Ohara T, Shaffer J R et al. Hair keratin mutations in tooth enamel increase dental decay risk. J Clin Invest 2014; doi: 10.1172/JCI78272. [Epub ahead of print].

\title{
CONCERN OVER LIMITED ACCESS TO WATER FLUORIDATION
}

The British Dental Association (BDA) and the British Society of Paediatric Dentistry (BSPD) have expressed concern that limited access to water fluoridation - only $10 \%$ of the UK's population - means we are failing children who live in communities with high levels of tooth decay.

In its latest report on fluoridation, the BSPD highlights that 60,683 children and adolescents in England were admitted to hospital in 2012/13 to have multiple decayed teeth removed under general anaesthetic, costing the NHS at least £27.6 million.

By contrast, evidence suggests that children living in fluoridated areas, such as the West Midlands, have around half the rate of tooth decay of those living in non-fluoridated areas,

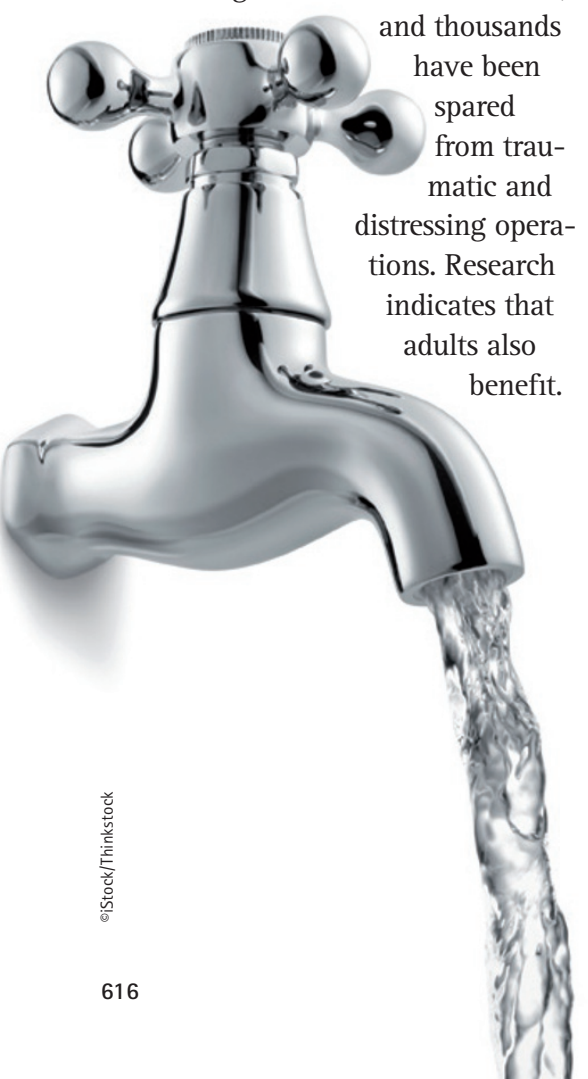

Despite these dramatic improvements in the oral health of children in areas where water is fluoridated, the BDA questions why a fluoridation scheme was recently abandoned in Southampton after being endorsed by Public Health England and a High Court ruling that the process in recommending water fluoridation had been lawful. The BDA is also concerned that water fluoridation was excluded from the NICE recommendations (published in October) for local authorities to consider when tackling high levels dental disease in their population.

The BDA's scientific adviser, Professor Damien Walmsley, said: 'Water fluoridation is safe and is one of the cheapest and most effective measures to reduce unacceptable inequalities of tooth decay, yet public debate on this is often reduced to misinformation and scaremongering with little or no regard to the communities affected most by this largely preventable disease',

The Chief Executive of the British Dental Health Foundation, Dr Nigel Carter, commented: 'It is disappointing to learn that Southampton City Council has given in to antifluoride protestors in the face of clear evidence from Public Health England on the benefits of fluoridation. [...] We will continue to lobby for nationwide fluoridation as we believe it is the biggest single action the Government can take to reduce and tackle tooth decay'.

To read the BSPD report on fluoridation, visit http://www.bspd.co.uk/ LinkClick.aspx?fileticket=ZDGNM_ $w H 7 D k \% 3 d c t$ tabid= 40 .

\section{COVER SERIES}

\section{A FINE FIGURE OF WARTIME SURGERY}

This issue's cover depicts a portrait of Sir William Kelsey Fry (18891963), a dental surgeon in the First World War and an important figure in the development of oral and maxillofacial surgery.

While dental services were not included in the medical provisions for soldiers, some doubly qualified dental surgeons such as Kelsey

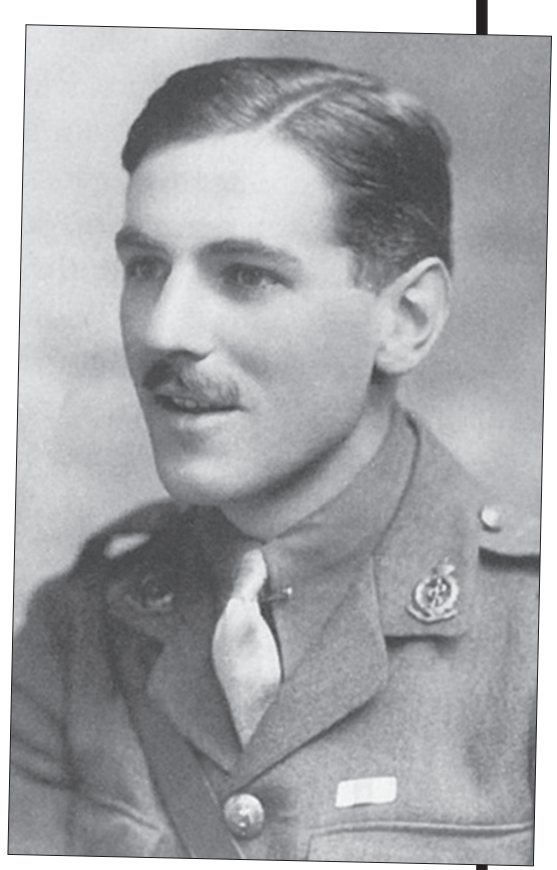

Fry served in the Royal Army Medical Corps (RAMC). In 1914 he was sent as a regimental medical officer to the Western Front where he was noted for his capability and bravery. Wounded twice in the line of duty, Kelsey Fry was sent back to England where he joined Harold Gillies' new plastic surgery unit at the Cambridge Military Hospital in Aldershot. In 1917 he moved with the unit to larger premises at Frognal House in Sidcup, becoming Chief Dental Surgeon of the newly established Queen's Hospital.

Gillies recognised the importance of a collaborative approach to facial injuries and therefore worked closely with his dental colleagues. With plastic surgery only just emerging as a specialty and maxillofacial surgery not yet fully developed, the distinction between the responsibilities of dental and plastic surgeons were often blurred. At Sidcup, Kelsey Fry was in charge of the dentists and dental technicians, and played an active role in designing the inventive dental prostheses that returned masticatory function to patients with jaw injuries. Under Kelsey Fry and Gillies, the Queen's Hospital became a centre for training in plastic and oral surgery for surgeons across the Commonwealth and America. In the Second World War, he went on to work alongside Archibald McIndoe (1900-1960) at the maxillofacial and plastic unit of the Queen Victoria Hospital in East Grinstead. Later in his life, Kesley Fry became a Lecturer in Oral Surgery at the Eastman Dental Institute and was knighted in 1951. 